\title{
Revitalizing Communal Role and Participation in Managing the Environment for Sustainable National Development.
}

\author{
REV. Dr. S.A. Ojeifo ${ }^{1}$, Dr. S. Aigbupue ${ }^{2}$ \\ ${ }^{I}$ (Department of Public Administration, Faculty of Management Sciences, Ambrose Alli University, Ekpoma, \\ Edo State, Nigeria. \\ ${ }_{2}^{2}$ (Department of Business Administration, School of Business Studies, Federal Polytechnic, Auchi, Edo State, \\ Nigeria.
}

\begin{abstract}
This paper explores the idea of revitalizing communal role and participation in managing the environment for sustainable national development and what this type of development can do to improve the quality of life within communities. The paper examines what sustainable development entails and provides examples of the threats to quality of life that traditional approaches to development can generate. In doing this, the paper examines the environmental management problems with its attendant implication for human health. The problems facing the urban and rural environment in Nigeria are complex that they have exceeded the capacity of government to handle alone. A critical look at the environment reveals the existence of sums/ghettos, unplanned and neglected environment which has resulted in the spread of diseases, social disorder, poor human development and low productivity. Community approach to managing the environment is considered pertinent because it is now widely realized that cooperation of all actors: the private sector, NGOs, communities and government is required to build the neglected and dilapidated environment. Sustainable development is vital to the health of communities and especially important to rural communities now under pressure from high energy and infrastructure costs. The study is based on secondary source of data. It recommended among others the adoption of community-based approach for effective management of the environment because it engenders high level of citizens' response to their commonly perceived problem of environmental decay.
\end{abstract}

Keywords: Community, Economic Development. Environmental-Management, Public-health, Waste.

\section{Introduction:}

As the society/ country grow wealthier, it has created more and more rubbish. According to the European commission on Environment, each year the European Union alone throw away 3 billion tunes of waste - Some 90 million tones being hazardous. According to the organization for Economic Cooperation and Development (OECS), most of what we throw away is either burnt in incinerators or dumped into landfill sites (67\%). But both these methods create environmental damage. Land filling not only takes up more and more valuable land space, it also causes air, water and soil pollution, discharging carbon dioxide $\left(\mathrm{Co}_{2}\right)$ and methane $\left(\mathrm{CH}_{4}\right)$ into the atmosphere and groundwater. This in turn is harmful to human health, as well as to plants and animals.

By 2020, the OECD estimates, we could be generating 45\% more waste than we did in 1995 . Obviously, we must reverse this trend if we are to avoid being submerged in rubbish. Therefore, environmental crisis will continue to be one of the most pressing problems facing humanity, especially the urban dwellers, in the $21^{\text {st }}$ century. The reason is because according to United Nations Centre for Human Settlement, UNCHS (1991), two thirds of the world's people will live in urban areas by the year 2025. With this, it is obvious that most of the world's gravest environmental threat to air quality, water quality and availability, waste disposal and energy consumption will be exacerbated by the high density and activities of urban life.

Expanding economic activities, increasing population growth, rising consumption and new methods of manufacturing, packaging and marketing are daily generating increasing volumes of waste. Furthermore, the absence of corresponding growth in the facilities for the management of waste has led to heaps of refuse that daunt the capacity of many municipal authorities. Excessive quantity of refuse and inefficient methods of their disposal result in epidemic and hazards to public health and safety; create public nuisance and depress the volumes of life, thereby interfering with community life and development.

The scale and complexity of the environmental problems in Nigeria are so immense that the government alone cannot handle them unassisted, given administrative weakness, corruption and bureaucratic bottlenecks found in the public sector (Achor 2001). All these imply that there is the need for the involvement of many actors in the management of the environment to complement the effort of the government and her agencies. This implies that community-based intervention will serve to augment the inadequate and erratic services and infrastructures being provided by public agencies and institutions. 
Revitalizing Communal Role And Participation In Managing The Environment For Sustainable

\section{Meaning of Community Participation in Environmental Management}

There are many definitions and there are many different ways for communities to attain a more sustainable future. The sustainability of a community depends on creating and maintaining its economic and environmental health, promoting social equity, and fostering broad - based citizen participation in planning and implementation. Communities that engage citizens and institutions to develop sustainability principles and a collective vision for the future and that apply an integrative approach to environmental, economic and social goals are generally likely to be more successful.

Job creation, energy use, transportation, education and health are considered complementary parts of the whole. Since all issues are interconnected they must be addressed as a system. This process includes: broad and diverse involvement of citizens, the creation of a collective vision for the future, the development of principles of sustainability etc.

Participation in this context connotes the voluntary involvement of people in making and implementing decisions directly affecting their lives and all the activities undertaken with or without external assistance to improve their living conditions, (UNCHS, 1991). Thornton (2000) sees Community participation as connoting the involvement of the residents of a defined area in the identification of their common problems and the fashioning out of mutually agreed solution to these problems. It means that members of the community are fully involved in both the planning of interventions and the implementation of the plans. In the low-income areas, the focus of community activities should be on seeking ways of improving the living conditions and quality of lives. Sustainability is a process of continuous improvement so communities constantly evolve and make changes to accomplish their goals that would make communities healthier, safer, greener, more viable and more prosperous. In this sense, sustainable development within a community redefines prosperity. It weights the values of community character, quality of life, and the environment along side economic development. Sustained development seeks what could be considered true development, recognizing that bigger is not always better. It understands the importance of long-term stewardship of community resources. Healthy communities pursue self-reliance and a more democratic approach to decision-making, placing community interests ahead of personal ones.

It is a clear assertion that the government acting alone cannot successfully address the challenges of environmental management. What is needed is a broad and all inclusive participation, building a synergy between government, non-governmental Organizations (NGOs) communities, household and the private sector to address the complicated human settlement questions which Okoro (2003) sees as an approach that facilities sustainable national development that is supported from the top down by the government and the community leaders, but implemented from the button up by citizens and civic groups.

According to Shadden (2000), the involvement of a broad range of actors in environmental management is fast becoming the vogue in many parts of the world. In fact, it is being promoted by the United Nations and other International Donor Agencies under the garb of 'urban governance' (UNCHS, 1996). This underscores the relevance of community participation in the management of the environment. According to Wang and Tong (2009), participation in environmental management and protection among community residents can be enhanced through creating awareness amongst the residents and stakeholders of the community.

\section{The Human Right to a Decent Living Environment}

During the 1980's, the concept of sustainable development emerged as a population solution to the problem of meeting the material needs of a rapidly growing population while minimizing environmental damage. Rather than pitting economic growth against environmental protection, proponents of sustainability focus on development which meets the needs of both present and future generations.

It is not in doubt there is an inseparable link between the quality of the environment and the health status of the residents. Whereas a decent living environment promotes good health, a deficient and inadequate environment predisposes individual to a range of both communicable and non-communicable diseases. Owing to the nexus between the environment and health, conscious provision of favorable factors in the environment will no doubt improve the health status of the residents of a locality. Indication that there exist human rights to a decent living environment can be gleaned from the stipulations of the Stockholm Declaration on Human Environment, 1972, which principle states that "Man has the fundamental right to freedom, equality and adequate condition of life in an environment of quality that permits a life of dignity and well being". In a similar view, the African Charter on Human and Peoples Rights, 1981 Article 24, clearly and unambiguously recognizes and provides for the right to a livable environment as a basic human right by stating that "all people shall have the right to a general satisfactory environment favourable to their development"

Since the environment plays a major role in moderating the health status of a people, it follows logically that the provision of the right to health certainly includes the right to a decent living and working environment. The task of ensuring that the provisions of the 'covenant' are realized for the citizens falls squarely upon the shoulders of government, which is a signatory to the covenant. The existence of unmitigated deplorable environmental conditions in our environment especially in the Niger-delta region of Nigeria are 
pointers to the failure of the Nigerian government in fulfilling her obligations in relation to Article 24 of the charter.

To underscore the status of the environment in Nigerian cities, some social statistics will be pertinent. According to the Federal Office of Statistics, only $24.5 \%$ of the Nigerian households had access to pipe bornewater in 1990. Also in 1990, only $9.1 \%$ of the citizens had access to the modern flush toilet whereas about $60.4 \%$ were still using pit latrines in the urban areas. In 1994, only $23 \%$ of the citizens disposed of their refuse through own or government provided waste bins whereas the greater majority just deposited their refuse clearly within the surrounding neighborhood. (Federal Office of Statistics, 1996). These scenarios pose a big challenge and in fact, a threat to the health and wellbeing of the citizens with their antecedent implication of national development.

IV. Effect of Environmental Problems on Health and Productivity

Tebibzadeh (1989) asserted that the interaction of poverty, polluted environment and pernicious overcrowding in our environment wreak havocs on the health status of the residents as there is high degree of morbidity from communicable diseases which are largely preventable, higher level of environment pollution, higher level of environmental filth, and poor nutritional status especially in low-income settlements. The following categories of disease are associated with environmental problems:

\subsection{Communicable Diseases}

This is engendered by poor housing system, respiratory and gastro enteric infections like pneumonia, respiratory tract infections, tuberculosis and bronchitis brought about by poor ventilation, overcrowding, high level of indoor pollution and dampness. There are also enteric infections (e.g. diarrhea, typhoid fever, dysentery and cholera) which are fostered by poor sanitation, contaminated water supplies, overcrowding, inadequate food hygiene, fly infestation and children defecating in the neighborhood, (UNHS, 1996). Moreover, inadequate neighborhood drainage system aids the transmission of malaria, even as poverty and illiteracy are prevalent in the spread of HIV infections.

\subsection{Non Communicable Diseases}

These are attributable to social factors like social marginalization, low social economic status, relative inequality and exclusion that play roles in causing non commutable disease like hypertensions, ulcer, drug abuse, smoking, violence, child abuse and alcoholism. Inadequate mass transit system, unsafe working environment, unprotected living neighborhood and unbridled exposure to vehicular traffic expose residents to accidents and other health hazards. (Tong. 1999).

\subsection{Mental Disorder}

Psychosocial and mental sickness like depression, anxiety and alcohol abuse attain high level of prevalence in the context of environmental stressors like noise, overcrowding, poorly maintained infrastructure and inadequately managed open space.

\subsection{Youth Problems and Juvenile Delinquencies}

These are issues involving prostitution, unsafe abortions, teenage pregnancies, gangsterism and violence in those areas due to inadequate sex education, limited access to health care and poverty.

\subsection{Psychological Problem}

These include mental conflicts, irritability, interpersonal clash, stress and depression.

\section{Approaches to Community Participation In Environmental Management For National Development}

Waste management planning is the cornerstone of any national, regional or local policy on waste management. Indeed, the establishment of a plan allows taking stock of the existing situation, to define the objectives that need to be met in the future to formulate appropriate strategies and identify the necessary implementation means.

Any approach to strengthening community participation in managing environment should consider the role of community residents, NGOs and governmental providers of environmental services. Such approaches include:

\subsection{Adoption of a Neighborhood Approach}

The residents need to understand that no mean full progress can be made until they start doing something positive about the environment themselves. It is through this means that they can arouse the interest and support of external agencies and the government. This entails knowing what environmental problems are, 
and their remedies followed by concerted action aimed at implementing the widely accepted solution. The residents need to first of all, explore the potentials of available local resources, skill and expertise in dealing with identified environmental problems.

\subsection{Community Capacity Building}

Through education and capacity building, the residents and opinion leaders will understand their rights and obligations. The community can be enjoined to participate in solving their collective environmental problems. Experts could be invited to help in this regard.

\subsection{Establishment of a Collective Platform}

This is a forum where residents can meet to discuss how to improve the environmental condition within neighborhood. This forum should be composed of representatives and encompasses all the interest groups in the community. There is need for election of officers to coordinate the improvement programme and form a liaison between the community and the tiers of government.

\subsection{Community Based Interventions} include:

This approach requires practice intervention to meet pressing needs in the community which should

(a.) Construction of latrines where they are lacking through the cooperation of landlords and tenants.

(b.) Provision of water supply through construction of wells or bore-holes by cooperative means or by mounting pressure on the government to connect the community to the city public water supply network.

(c.) Provision of containers for proper refuse disposal and prompt disposal of waste by governmental agencies on a regular basis, and as at when due.

(d.) Construction of drainage channel with the cooperation of the various tiers of government.

(e.) Periodic assessment and supervision of the neighborhood environment undertaken by the appointees of the community.

\subsection{Partnering with NGOs}

Such NGOs, according to Achor (2003) usually provide support to the community by acting as community organizers, advocates for improvement, technical consultants or providers of financial leverage. The NGOs may assist in the:

(i.) Provision of legal defense to victims of environmental/human right abuses;

(ii.) Capacity building for the community as well as its residents and various groups;

(iii.) Monitoring and reporting of environmental deficiencies; and

(iv.) Facilitating the provision of environmental services by individuals and local groups.

\subsection{Benefits of Community Participation in Environmental Management}

The essence of stressing community participation in environmental management is to foster higher level of involvement of the citizens in the quest for better living conditions. This is considered germane because it is not widely realized that cooperation of all is needed to upgrade the environment (UNCHS, 1994). Essentially, the objectives that community participation tends to achieve according to Milton and Thompson (1995) are to:

(i.) Identify and prioritize the needs of the people;

(ii.) Mobilize resources for meeting the identified needs;

(iii.) Engender consultation, communication and collective capacity building;

(iv.) Create awareness about the role of key actors involved in local level development; and

(v.) Foster mechanism for conflict resolution and consensus-building in a neighborhood.

It is apparent from the foregoing that the institution of participation approach to environmental management leads to a number of benefits. For instance, it increases access to decision making process; a considerable degree of empowerment, accountability and improved efficiency since community directed and managed projects are more cost effective. Furthermore, it reduces the tendency to corruption, increased willingness by resident to pay for environmental related services which on the long-run guarantees national development and sustainability. The gains of community participation in environmental management, as asserted by Achor (2001) include:

(i.) Engendering community cohesion, security and creative use of local resources;

(ii.) Providing an opportunity for communities to relate with public officials and donor agencies

(iii.) Providing avenue for conflict resolution and consensus building

(iv.) Fostering community empowerment, capacity and confidence building and self-reliance; and

(v.) Giving residents an opportunity to take action and solve their collective problems. 


\section{Reasons for Strengthening Community Participation}

\section{In Environmental Management}

There is no doubt that the sooner communities, different tiers of government and partnership among the public, private and community are involved to create comprehensive, bold and innovative strategies for shelter and human settlement, the better the prospects will be for the safety, health and wellbeing of residents of the community. Adoption of any or a combination of the under-mentioned approaches hold the potential for providing innovative and pragmatic solutions to the environmental problems facing many Nigerian cities owing to the ideals on which the approaches hinge.

\subsection{Community Organization}

This approach usually helps communities to get organized and affiliated to recognizable groupings. Such organizations facilitate the selection of representatives, collection of levies, payment for services, project administration, and accountability.

\subsection{Representative Administration}

This approach promotes popular cooperation and accountability. It thrives in the context of democratic, accountable, transparent and people-oriented government at the different tiers. This is the reason for promoting this form of participation alongside good governance and democracy by international agencies.

\subsection{Efficient use of Locally Generated Resources}

Since this is based on leveraging the available local resources in term of finance, technical and organizational expertise, and other human and economic resources, cost reduction and self-reliance are encouraged.

\subsection{Partnering with NGOs}

Many NGOs are willing and capable of helping communities that are pursuing participatory programmes. They can contribute in capacity building, community organizing, and as consultants. These support services foster effective participation of the need of communities and enhance the chance of receiving assistance from government and the donor agencies.

\section{Summary and Conclusion}

It is pertinent to state that one of the factors that distinguished human from lower animal is that human beings protect their habitat. Ken Saro Wiwa (1941-1995) gave his life for the sake of giving public attention to environmental problems. We either get together to maintain our environment or the forces of nature will maintain us. Ofei (2002) opined that there is urgent need for popular participation in improving the environment. He argued that time has passed when the issue would be left for environmental activists alone especially the elites in the society since it is most unrealistic that the hungry and homeless people will divert their energy to looking for food to ecological problems, as closely linked as they are.

\subsection{Recommendation}

In order to strengthen community participation in environmental management for national development, a combination of the identified approaches which include adoption of neighborhood approach, community capacity building, establishment of collective platform, community-based intervention, partnering with NGOs among others should be vigorously pursued. This is what is currently in vogue in some West African countries, such as Senegal, where according to Gaye and Diallo (2010), inhabitants themselves, in partnership with an NGOs (EDNA-Tiers Monde), with local authorities and support from other agencies, solved problems of inadequate water supply, sanitation, drainage, and the collection and disposal of garbage in nine low-income communities in Rusfique, Senegal. The use of such approaches encourages empowerment of residents, effective resources mobilization, and enhancement of confidence as well as long term sustainability of environmental services delivery. All that is needed is a transparent and accountable leadership in the various tiers of government. 


\section{Journal Papers:}

\section{References}

[1] Achor, J., The Human Costs of Slum Habitation in Lagos in Health Update, Shelter Rights Initiative, Vol. (3) June - December, 2001.

[2] Arotiba, Slum Settlement and Waste Management in Lagos State in Health Update by Shelter Rights Initiative, Vol. 1 (3) 2001.

[3] Gaye, M and Diallo, F., Community Participation in the Management of Urban Environment in Rusfisque, Senegal - Sage Journal of Environment and Urbanization, June Vol. 22 No. 1, 2010.

[4] George, C. K., The Growth of Lagos Metropolis and the resulting Challenges of Urban renewal. Shelter Right Initiative, Lagos, Vol. 1, 2002.

[5] Mitlin, D and Thompson, Participatory Approach in Urban Areas: Strengthening Civil Society or Enforcing the Status Quo, Environment and Urbanization Vol. 7 (1), 1995.

[6] Okoro, D, The Human Costs of Slum Habitation in Lagos. Shelter Right Initiative Vol. 1 (3) Lagos, 2001.

[7] Onyeagu, R., Housing Right Implication of Violation of Right to Adequate Housing. LASER Contact, Shelter Rights Initiative Vol. 5 (1) Jan-June, 2000.

[8] Shadden, T., Environmental Related Human Diseases indicators: Australian Journal of Environmental Health. June, 2000.

[9] Tong, S., Major Issues in the Environmental Health Decision Making Process: Journal, 2009.

[10] Thornton, P.D., How to Set Outcome Indicators: Journal of Environmental Health. March, 2000.

[11] Wang, H. and Tong, M., "Community Participation in Environmental Management of ecotourism" International Journal of Business and Management. Vol. 4 No. 3, 2009.

Books:

[12] Onyekpere, E. (2000) The Homeless Millions: Forced Eviction in Rainbow Town Port Harcourt, Shelter Right Initiative, Lagos.

[13] Tibibzedeh A. (1989) Cited in Managing the Environment in Popular Neighborhood in Achor (ed). Shelter Rights Initiative. Lagos.

\section{Proceeding Papers:}

[14] Ofei, U. (2002) The Need for popular Participation in Improving the Slum Environment. An Address Presented at Public Presentation of SRI's Practical Issues in Human Settlements and Health.

[15] UNCHS (1996) An Urbanizing World: Global Report on Human Settlements, Nairobi, United Nations Centre for Human Settlement. (UNCHS).

[16] Achor, J. (2003) A Case Study Lagos Slum Neighborhood Incremental Improvement Programme, Socio-Economic Rights Initiative: Lagos.

[17] Agbanu M. (1997) Implementing the Urban Environment Agenda in Vol. 1 of Environmental Planning and Management Source Book Published by the United Nations Centre for Human Settlements (UNCHS) and United Nations Environmental Programme (UNEP).

[18] UNVHS (1991) Humans Settlement Through Community Participation, Nairobi: United NATIONS Centre for Human Settlement (UNCHS).

[19] WHO (1993) The Urban Health Crisis: Strategies for Health for All in the Face of Rapid Urbanization, Geneva.

[20] World Bank (1995) Restoring Urban Nigeria: A strategy for Restoring Urban Infrastructure and Service in Nigeria. Washington D.C.

[21] Concern@sustainable.orgconcern@sustainable.org

[22] http://ec.europe.eu/environment/waste/pdf/waste

[23] http://www.spawlcity 